\title{
Study the hydro and thermal performance of microchannel heat exchanger with hybrid suspension of nanoparticles and MEPCM particles
}

\author{
Mushtaq Ismael Hasan ${ }^{\dagger}$, Mohammad Jazaa Khafeef ${ }^{\ddagger}$ \\ 'First author's Mechanical Engineering, College of Engineering, Thi-Qar University, Iraq \\ ‘Second author’s Mechanical Engineering, College of Engineering, Thi-Qar University, Iraq
}

\begin{abstract}
This paper aims to study the flow and heat transfer of hybrid suspension in counter flow micro channel heat exchanger (CFMCHE). In order to enhance the thermal properties of micro encapsulated phase change material (MEPCM) suspension. The hybrid suspension studied in this paper consists of nanoparticles and MEPCM particles, these particles are suspended in water as abase fluid, two types of hybrid suspension are used $(\mathrm{Cu}+\mathrm{MEPCM}$ suspension) and $\left(\mathrm{Al}_{2} \mathrm{O}_{3}+\mathrm{MEPCM}\right.$ suspension) by n-octadecane as a PCM for both of them. The hydrodynamic and thermal characteristics of thes suspensions flow in micro channels of CFMCHE is numerically investigated. From obtained results, using of hybrid suspensions as a cooling fluid lead to modify thermal performance of a CFMCHE by increase its effectiveness but it also lead to high increasing in pressure drop. The results showed considerable enhancement in cooling effectiveness of $\left(\mathrm{Al}_{2} \mathrm{O}_{3}+\right.$ MEPCM suspension $)$ above of the pure PCM suspension, Nanofluids, and water. While $(\mathrm{Cu}+\mathrm{MEPCM}$ suspension) showed enhancement above of the pure PCM suspension and water, but was not best effectiveness than Nanofluids. Extra increase in pressure drop in both types of hybrid suspension above are leads to reduce the overall performance compared with pure PCM suspension. Therefore its use depends on the application at which this heat exchanger is employed.
\end{abstract}

Key words: Microchannel heat exchanger (MCHE), Microencapsulated phase change material (MEPCM), Phase change materials (PCM), hybrid suspension, Nanofluid.

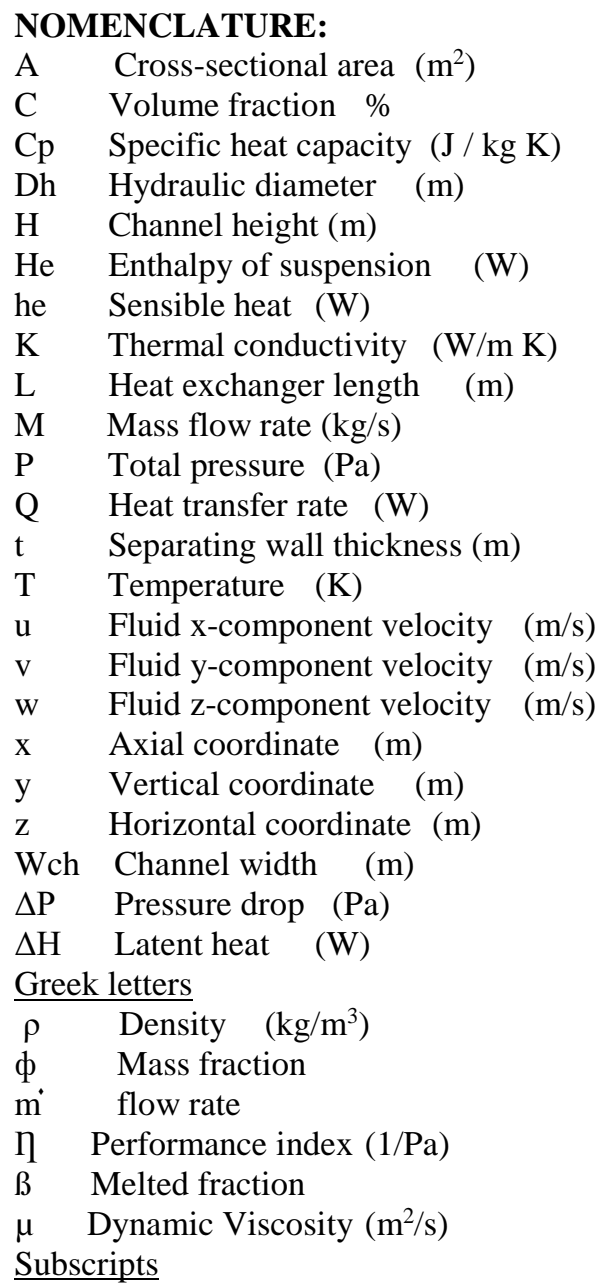


c Cold

f Suspension

h Hot

i Inlet

ch Channel

Max. Maximum

o Outlet

p Particle

t Total

\section{Introduction}

Microchannel heat exchanger (MCHE) is one of most important application in thermal system because it can remove large amount of heat on a small volume. And the dimensions of microchannels range varied between $1 \mathrm{~mm}$ to $1 \mu \mathrm{m}$. There are many materials can be used by manufacturing microchannel as metals, glass, polymers, silicon... etc.

Cooling fluids play a main role in cooling applications, for being one of the methods for enhancing heat transfer, the basic idea is to enhance heat transfer rate by changing the fluid transport properties from through the application of additives to the working fluids.

There are many researches about microchannel heat exchangers and role of cooling fluids, such as; Mushtaq I. Hasan et al. (2009)[1] studied the effect of channel geometry on the performance of a counter flow microchannel heat exchanger (CFMCHE) using numerical simulation. Thier study included five different shapes (rectangular, square, triangular, trapezoidal and circle) with using water as working fluid. The findings refer to decrease in volume of channel or increase number of channels in a CFMCHE, as leads to increase in heat transfer rate, pressure drop and effectiveness. Effect of various channels shapes on heat transfer rate and pressure drop are adopted to show that the circular shape gives the best overall performance following by the square channels. C. J. Ho et al. (2010)[2] prepared the hybrid water-based suspension as a functional forced convection fluid consist of $\mathrm{Al}_{2} \mathrm{O}_{3}$ nanoparticles and MEPCM particles. The thermal properties of hybrid suspension including the thermal conductivity, density, specific heat, dynamic viscosity, and latent heat of fusion were investigated experimentally. They found that increasing in fraction of $\mathrm{Al}_{2} \mathrm{O}_{3}$ nanoparticles can be improve the intrinsic characteristics of low thermal conductivity of the pure PCM suspension, resulting even in significantly boost thermal conductivity relative to the water. Mushtaq I. Hasan (2011)[3] have numerical investigated on microchannel heat exchanger with microencapsulated phase change material suspension. The MEPCM suspension used in his research contains of microcapsules constructed from the shell material of polymethylmethacrylate and n-octadecane as a PCM. These capsules are suspended in pure water by a concentration varied from (0 to 20$) \%$. It found that, using of MEPCM suspensions as a cooling medium led to modify thermal performance of a CFMCHE but it also led to increase the pressure drop heavily. As well, it is better to use the MEPCM suspension with low velocity to obtain the benefits of melting of phase change materal (PCM) and releasing the latent heat. C. J. Ho et al. (2011)[4] investigated experimentally the hybrid suspensions of $\mathrm{Al}_{2} \mathrm{O}_{3}$ nanoparticles and MEPCM particles on laminar convective cooling performance in a circular tube. Their results showed, great enhancement in cooling effectiveness of the hybrid suspension compared with the pure PCM suspension, water, or nanofluid. However, the convection effectiveness of utilizing the hybrid suspension appears mightily outweighed by pressure drop penalty from its higher viscosity with respect to the pure nanofluid or the pure PCM suspension. C. J. Ho et al. (2011)[5] investigated experimentally the thermal performance of hybrid suspension of $\mathrm{Al}_{2} \mathrm{O}_{3}$ nanoparticles and MEPCM particles in a mini-channel heat sink. The mini-channel heat sink was heated with base heat flux in the Reynolds numbers from 133 to 1515 . They used mass fractions of MEPCM particles and nanoparticles to dispersed in the water-based suspensions in the ranges of $2-10 \mathrm{wt} \%$. They obtained, the heat dissipation effectiveness of hybrid suspension depends great on flow rates during the heat sink. For the nanofluid, the maximum enhancement of $57 \%$ in the averaged heat transfer coefficient was found under the highest flow rate. For the hybrid suspension, they found that effect of simultaneous dispersion of the nanoparticles and MEPCM particles in pure water appears to be supplementary with added usefulness of simultaneous increases in the specific heat and effective thermal conductivity such that the heat transfer effectiveness could be further the increased up to $56 \%$ with little dependence on the flow rate. Mushtaq I. Hasan et al. (2012)[6] numerically investigated of a CFMCHE performance with using nanofluid as a cooling fluid. Two types of nanofluids ( $\mathrm{Cu}$-water and $\mathrm{Al}_{2} \mathrm{O}_{3}$-water) were studied with concentrations ( $1 \%$ to $5 \%$ ). They found that using the nanofluids as cooling medium lead to enhance the thermal performance of CFMCHE. With no added increase in pressure drop becouse of the ultra fine solid particles and low volume fraction concentrations. Also they found that, nanofluid led to absorb more heat than water with low flow rates. Whereas in high flow rates the heat transfer was dominated through the volume flow rate and nanoparticles did not contribute in the high heat absorption. Also, they concluded that performance of CFMCHE can be increased significantly by using nanofluids with higher thermal conductivities. Nabeel $\mathrm{S}$. Dhaidan et al. (2013)[7] investigated numerically and experimentally the melting of phase change material/nanoparticle suspensions in a square shape container and under effect a constant heat flux. They used 
the n-octadecane as a PCM with $\mathrm{CuO}$ nanoparticle suspensions and were the container subjected to a constant heat flux on one side, whereas the other sides are thermally insulated. The results showed that the nanoparticle loading lead to raising in thermal conductivity of the PCM/nanoparticle composite, hence increase heat transfer rate that lead to decrease in the charging time. Also the results indicate to caution should be taken for great values of nanoparticle concentration because effects of increasing viscosity and possibility of precipitation and agglomeration. Thereby, that dispersing a suitable concentration of nanoparticles in PCM has large ability for improving thermal energy storage systems. S. Manikandan, K.S. Rajan (2017)[8] used new hybrid nanofluid containing sand nanoparticles and encapsulated paraffin wax in propylene glycol-water mixture. They used Paraffin wax has a melting point range of (58-60), and double distilled water, and pluronic P-123 to preparate hybrid nanofluid, which consists of sand nanoparticles (1 vol.\%) and pluronic P-123 encapsulated paraffin wax (70$120 \mathrm{~nm}$ diameter, 1-5 wt.\%) in propylene glycol-water mixture. Thier results show that, addition of pluronic P123 encapsulated paraffin wax led to improve in the specific heat, and the presence of sand nanoparticles resulted to improve thermal conductivity. Hence, the hybrid nanofluid consisting of $1 \mathrm{wt} . \%$ paraffin wax and 1 vol.\% sand nanoparticles led to $9.6 \%$ enhancement in thermal conductivity and $18 \%$ decreasing in viscosity, without decrease in specific heat in comparison with propylene glycol-water mixture. Thus, be the most suitable alternative for propylene glycol-water mixture, and can be used in solar thermal systems as a substitute for propylene glycol-water mixture. In this paper a hybrid suspension is used as a cooling medium in counter flow microchannel heat exchanger.

Objective of the paper is using hybrid suspension for improve the intrinsic characteristics for pure PCM suspension.

\section{Mathematical model:}

Fig.1 represents the schematic structure of the studied CFMCHE with square channels carrying hot and cold fluids. To study of complete CFMCHE numerically it is complicated and need huge of run time. Because of the geometrical and thermal symmetry between cold and hot channels rows, an individual heat exchange cell consists of two channels which containing cold and hot fluids and a separating wall as shown in Fig. 2. Will be used as a model to represent the full counter flow microchannel heat exchanger since it give an adequate indication for its performance[1,9].

The assumptions used to solve this model are $(3 \mathrm{D}$, laminar, steady state, incompressible fluid, continuum flow, constant properties and no heat transfer tolfrom the ambient
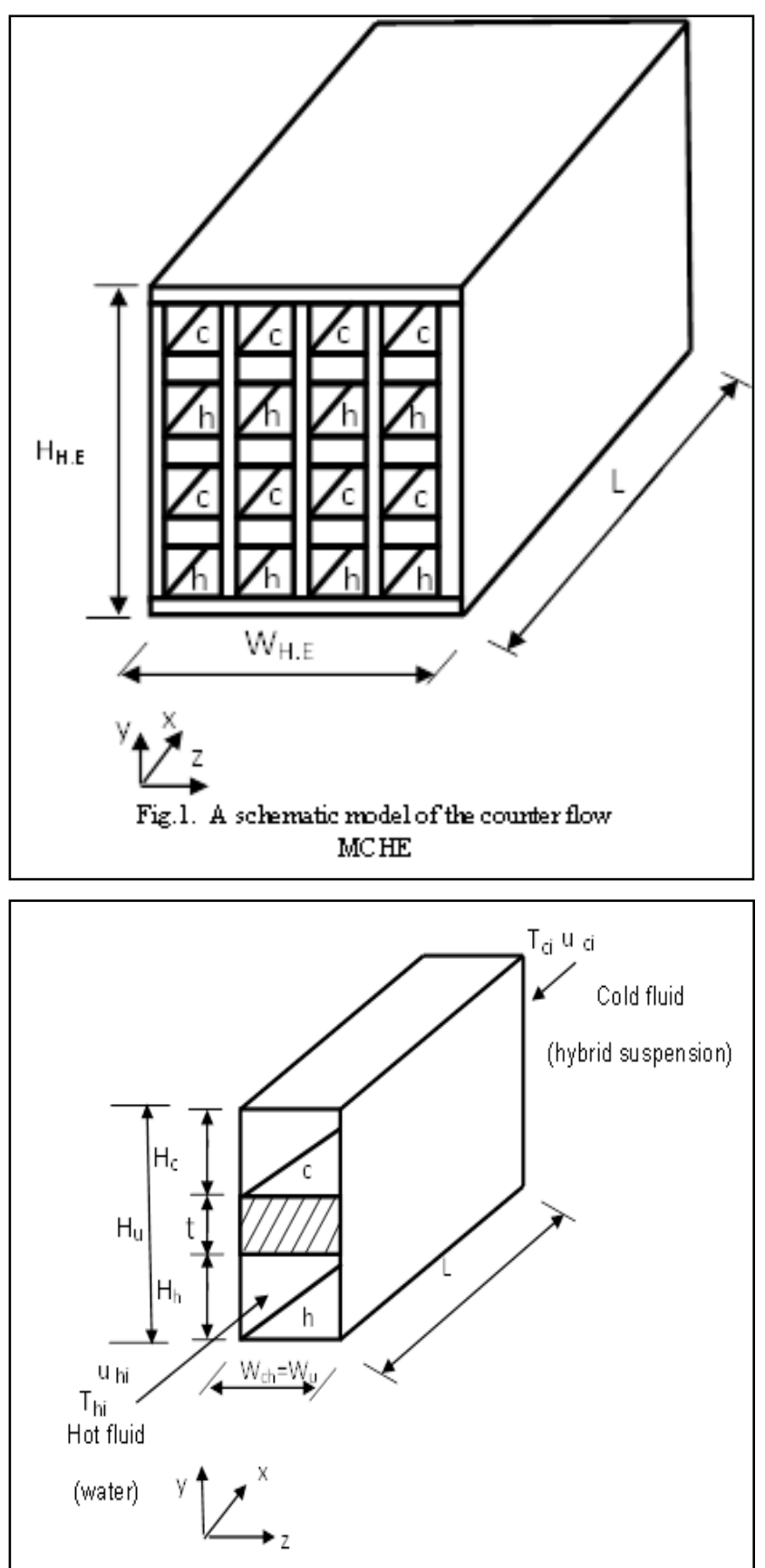

Fig. 2 A schematic of heat exchange cell

\section{Governing equations:}

The governing equations are represented by continuity, momentum, and energy for flow of pure fluids, nanofluid, microencapsulstd phase change materials suspension, and hybrid suspension can be written as following $[3,10,11]$.

3.1. Governing equations for pure water and nanofluids: The continuity equation

$\frac{\partial u_{j}}{\partial x}+\frac{\partial v_{j}}{\partial y}+\frac{\partial w_{j}}{\partial z}=0$

Momentum equations 
$u_{j} \frac{\partial u_{j}}{\partial x}+v_{j} \frac{\partial u_{j}}{\partial y}+w_{j} \frac{\partial u_{j}}{\partial z}=-\frac{1}{\rho_{j}} \frac{\partial P}{\partial x}+\frac{\mu_{j}}{\rho_{j}}\left(\frac{\partial^{2} u_{j}}{\partial x^{2}}+\frac{\partial^{2} u_{j}}{\partial y^{2}}+\frac{\partial^{2} u_{j}}{\partial z^{2}}\right) \cdots$

$u_{j} \frac{\partial v_{j}}{\partial x}+v_{j} \frac{\partial v_{j}}{\partial y}+w_{j} \frac{\partial v_{j}}{\partial z}=-\frac{1}{\rho_{j}} \frac{\partial P}{\partial y}+\frac{\mu_{j}}{\rho_{j}}\left(\frac{\partial^{2} v_{j}}{\partial x^{2}}+\frac{\partial^{2} v_{j}}{\partial y^{2}}+\frac{\partial^{2} v_{j}}{\partial z^{2}}\right) \cdots$

$u_{j} \frac{\partial w_{j}}{\partial x}+v_{j} \frac{\partial w_{j}}{\partial y}+w_{j} \frac{\partial w_{j}}{\partial z}=-\frac{1}{\rho_{j}} \frac{\partial P}{\partial z}+\frac{\mu_{j}}{\rho_{j}}\left(\frac{\partial^{2} w_{j}}{\partial x^{2}}+\frac{\partial^{2} w_{j}}{\partial y^{2}}+\frac{\partial^{2} w_{j}}{\partial z^{2}}\right) \cdots$

Where $\mathrm{j}=\mathrm{c}$ and $\mathrm{h}$ for cold and hot fluids respectively.

The energy equation for fluids in heat exchanger:

$\rho C p\left(u \frac{\partial T}{\partial x}+v \frac{\partial T}{\partial y}+w \frac{\partial T}{\partial z}=k\left(\frac{\partial^{2} T}{\partial x^{2}}+\frac{\partial^{2} T}{\partial y^{2}}+\frac{\partial^{2} T}{\partial z^{2}}\right)\right.$

The energy equation for solid walls in heat exchanger:

$k_{s} \nabla^{2} T_{s}=0$

3.2. Governing equations for MEPCM and hybrid suspensions:

The governing equations used for pure fluid from (1to 4 ) and 6 above are the same as in section 3.1.

The energy equation based upon enthalpy is:

$\nabla \cdot\left[\vec{V}\left(\rho_{f} H_{e}\right)\right]=\nabla .\left(k_{f} \nabla T_{f}\right)$

and can be written as:

$\rho_{f}\left[u \frac{\partial H_{e}}{\partial x}+v \frac{\partial H_{e}}{\partial y}+w \frac{\partial H_{e}}{\partial z}\right]=k_{f}\left[\frac{\partial^{2} T_{f}}{\partial x^{2}}+\frac{\partial^{2} T_{f}}{\partial y^{2}}+\frac{\partial^{2} T_{f}}{\partial z^{2}}\right]$

The enthalpy of the suspension (He) is showed by equation (9) and computed as follows:

$\mathrm{He}=\mathrm{he}+\Delta \mathrm{H}$

The sensible heat is calculated by equation (10), where href is the reference enthalpy at Tref [11].

$h_{e}=h_{r e f}+\int_{T_{r e f}}^{T} C p_{f} d T$

The latent heat of the slurry $(\Delta \mathrm{H})$ is calculated by equation $(11)$, where $(\beta)$ is the melted mass fraction, ( $\phi)$ MEPCM mass fraction, (L) latent heat of the PCM.

$(\beta)$ is the mass ratio of melted phase change material (PCM) to the total mass of phase change material (PCM) in the slurry. The PCM begins to melt at $\mathrm{T}_{\text {solidus }}$ till completely melts at $\mathrm{T}_{\text {lquidus }}$ where the liquid fraction can change from zero at $\mathrm{T}_{\text {solidus }}$ to one at $\mathrm{T}_{\text {lquidus }}$.

$\Delta \mathrm{H}=\beta \phi L$

Where:

$$
\begin{aligned}
& \beta=0 \quad \text { if } \quad \mathrm{T}_{\mathrm{f}}<\mathrm{T}_{\text {solidus }} \\
& \beta=1 \quad \text { if } \quad \mathrm{T}_{\mathrm{f}}>\mathrm{T}_{\text {lquidus }} \\
& \beta=\frac{T_{f}-T_{\text {solidus }}}{T_{\text {liquidus }}-T_{\text {solidus }}} \text { if } \mathrm{T}_{\text {solidus }}<\mathrm{T}_{\mathrm{f}}<\mathrm{T}_{\text {lquidus }} \ldots
\end{aligned}
$$

\subsection{Model boundary conditions:}

The working fluids enters the channels in a defined temperature and velocity. For MEPCM particles temperature increases as it flow through the channels till reaches the melting temperature of phase change material (PCM). When the PCM melting inside the capsules, the melted PCM remains contained in the capsules and will not mixed with the base fluid. Hence, the carrier fluid shown lower temperature change when the PCM melts. The hot fluid is considered as water while cold fluid tested as (pure water, nanofluid, MEPCM suspension, and hybrid

\begin{tabular}{|c|c|c|}
\hline Location & Boundary condition & Comments \\
\hline at $x=0$ & $\begin{array}{l}\mathrm{u}_{\mathrm{h}}=\mathrm{u}_{\mathrm{hi}}, \mathrm{v}_{\mathrm{h}}=\mathrm{w}_{\mathrm{h}}=0 \\
\mathrm{~T}_{\mathrm{h}}=\mathrm{T}_{\mathrm{hi}}\end{array}$ & hot fluid inflow \\
\hline at $\mathrm{x}=\mathrm{L}$ & $\begin{array}{l}\frac{\partial u_{h}}{\partial x}=v_{h}=w_{h}=0 \\
\frac{\partial T_{h}}{\partial x}=0\end{array}$ & $\begin{array}{l}\text { hot fluid } \\
\text { outflow (fully } \\
\text { developed } \\
\text { flow, end of } \\
\text { channel ) } \\
\end{array}$ \\
\hline at $y=0$ & $\begin{array}{l}\mathrm{u}_{\mathrm{h}}=\mathrm{v}_{\mathrm{h}}=\mathrm{w}_{\mathrm{h}}=0 \\
\frac{\partial T_{h}}{\partial y}=0\end{array}$ & $\begin{array}{l}\text { no-slip, } \\
\text { adiabatic wall }\end{array}$ \\
\hline at $\mathrm{y}=\mathrm{H}_{\mathrm{h}}$ & $\begin{array}{l}\mathrm{u}_{\mathrm{h}}=\mathrm{v}_{\mathrm{h}}=\mathrm{w}_{\mathrm{h}}=0 \\
,-k_{h} \frac{\partial T_{h}}{\partial y}=-k_{s} \frac{\partial T_{s}}{\partial y}, \\
\mathrm{~T}_{\mathrm{h}}=\mathrm{T}_{\mathrm{s}}\end{array}$ & $\begin{array}{l}\text { fluid -solid } \\
\text { interface (no- } \\
\text { slip, conjugate } \\
\text { heat transfer) }\end{array}$ \\
\hline at $\mathrm{z}=0$ & $\begin{array}{l}\mathrm{u}_{\mathrm{h}}=\mathrm{v}_{\mathrm{h}}=\mathrm{w}_{\mathrm{h}}=0 \\
\frac{\partial T_{h}}{\partial z}=0\end{array}$ & $\begin{array}{l}\text { no-slip, } \\
\text { adiabatic wall }\end{array}$ \\
\hline at $\mathrm{z}=\mathrm{W}_{\mathrm{ch}}$ & $\begin{array}{l}\mathrm{u}_{\mathrm{h}}=\mathrm{v}_{\mathrm{h}}=\mathrm{w}_{\mathrm{h}}=0 \\
\frac{\partial T_{h}}{\partial z}=0\end{array}$ & $\begin{array}{l}\text { no-slip, } \\
\text { adiabatic wall }\end{array}$ \\
\hline
\end{tabular}
suspension) The boundary conditions used are:

Lower channels (hot fluid) $(0 \leq \mathrm{y} \leq \mathrm{Hh})$

\begin{tabular}{|c|c|c|}
\hline Location & Boundary condition & Comments \\
\hline at $\mathrm{x}=0$ & $\begin{array}{l}\frac{\partial u_{c}}{\partial x}=v_{c}=w_{c}=0 \\
\frac{\partial T_{c}}{\partial x}=0\end{array}$ & $\begin{array}{l}\text { cold fluid } \\
\text { outflow (fully } \\
\text { developed } \\
\text { flow, end of } \\
\text { channel }\end{array}$ \\
\hline at $\mathrm{x}=\mathrm{L}$ & $\begin{array}{l}\mathrm{u}_{\mathrm{c}}=\mathrm{u}_{\mathrm{ci}}, \mathrm{v}_{\mathrm{c}}=\mathrm{w}_{\mathrm{c}}=0 \\
, \mathrm{~T}_{\mathrm{c}}=\mathrm{T}_{\mathrm{ci}}\end{array}$ & $\begin{array}{l}\text { cold fluid } \\
\text { inflow }\end{array}$ \\
\hline at $y=\mathrm{H}_{\mathrm{h}}+\mathrm{t}$ & $\begin{array}{l}\mathrm{u}_{\mathrm{c}}=\mathrm{v}_{\mathrm{c}}=\mathrm{w}_{\mathrm{c}}=0, \\
-k_{c} \frac{\partial T_{c}}{\partial y}=-k_{s} \frac{\partial T_{s}}{\partial y} \\
, \mathrm{~T}_{\mathrm{c}}=\mathrm{T}_{\mathrm{s}}\end{array}$ & $\begin{array}{l}\text { fluid-solid } \\
\text { interface (no- } \\
\text { slip, conjugate } \\
\text { heat transfer) }\end{array}$ \\
\hline at $\mathrm{y}=\mathrm{H}_{\mathrm{h}}+\mathrm{t}+\mathrm{H}_{\mathrm{c}}$ & $\begin{array}{l}\mathrm{u}_{\mathrm{c}}=\mathrm{v}_{\mathrm{c}}=\mathrm{w}_{\mathrm{c}}=0 \\
\frac{\partial T_{c}}{\partial y}=0\end{array}$ & $\begin{array}{l}\text { no-slip, } \\
\text { adiabatic wall }\end{array}$ \\
\hline at $\mathrm{z}=0$ & $\begin{array}{l}\mathrm{u}_{\mathrm{c}}=\mathrm{v}_{\mathrm{c}}=\mathrm{w}_{\mathrm{c}}=0 \\
\frac{\partial T_{c}}{\partial z}=0\end{array}$ & $\begin{array}{l}\text { no-slip, } \\
\text { adiabatic wall }\end{array}$ \\
\hline at $\mathrm{z}=\mathrm{W}_{\mathrm{ch}}$ & $\begin{array}{l}\mathrm{u}_{\mathrm{c}}=\mathrm{v}_{\mathrm{c}}=\mathrm{w}_{\mathrm{c}}=0 \\
\frac{\partial T_{c}}{\partial z}=0\end{array}$ & $\begin{array}{l}\text { no-slip, } \\
\text { adiabatic wall }\end{array}$ \\
\hline
\end{tabular}

Upper channel (cold fluid) $(\mathrm{Hh}+\mathrm{t} \leq \mathrm{y} \leq \mathrm{Hh}+\mathrm{t}+\mathrm{Hc})$

Solid wall separating two channels $(\mathrm{Hh} \leq \mathrm{y} \leq \mathrm{Hh}+\mathrm{t})$ 


\begin{tabular}{|l|l|l|}
\hline Location & Boundary condition & Comments \\
\hline at $\mathrm{x}=0$ & $\frac{\partial T_{s}}{\partial x}=0$ & adiabatic wall \\
\hline at $\mathrm{x}=\mathrm{L}$ & $\frac{\partial T_{s}}{\partial x}=0$ & adiabatic wall \\
\hline at $\mathrm{y}=\mathrm{H}_{\mathrm{h}}$ & $-k_{h} \frac{\partial T_{h}}{\partial y}=-k_{s} \frac{\partial T_{s}}{\partial y}$ & $\begin{array}{l}\text { fluid - solid } \\
\text { interface }\end{array}$ \\
\hline at $\mathrm{y}=\mathrm{H}_{\mathrm{h}}+\mathrm{t}=\mathrm{T}_{\mathrm{s}}$ & $-k_{c} \frac{\partial T_{c}}{\partial y}=-k_{s} \frac{\partial T_{s}}{\partial y}$ & $\begin{array}{l}\text { fluid - solid } \\
\text { interface }\end{array}$ \\
\hline at $\mathrm{z}=0$ & $\frac{\partial T_{s}}{\partial z}=0$ & adiabatic wall \\
\hline at $\mathrm{z}=\mathrm{W}_{\mathrm{ch}}$ & $\frac{\partial T_{s}}{\partial z}=0$ & adiabatic wall \\
\hline
\end{tabular}

A finite volume method (FVM) has been used to solve the mentioned governing equations and boundary conditions numerically. Computational fluid dynamics (CFD) has used to solve this model and calculate the distribution of the flow velocity, temperature and pressure in a CFMCHE. And the square channel with length $\mathrm{W}=10$ $\mathrm{mm}$, width $\mathrm{L}=100 \mu \mathrm{m}$, channel height $\mathrm{H}=100 \mu \mathrm{m}$, wall thickness $\mathrm{t}=50 \mu \mathrm{m}$.

Then the following performance parameters have been calculated:

Heat exchanger effectiveness is the ratio of the actual heat transfer to the maximum possible heat that can be transferred:

$$
\varepsilon=\frac{q}{q_{\max }}
$$

Where :

$\mathrm{q}_{\max }=\mathrm{C}_{\min }\left(\mathrm{T}_{\mathrm{hi}}-\mathrm{T}_{\mathrm{ci}}\right)$

and

$\mathrm{q}=\mathrm{C}_{\mathrm{h}}\left(\mathrm{T}_{\mathrm{hi}}-\mathrm{T}_{\mathrm{ho}}\right)=\mathrm{C}_{\mathrm{c}}\left(\mathrm{T}_{\mathrm{co}}-\mathrm{T}_{\mathrm{ci}}\right)$

Where: $C_{c}=m C p_{c}$ and $C_{h}=m C p_{h}$

The total pressure drop in heat exchange cell is:

$\Delta \mathrm{Pt}=\Delta \mathrm{Ph}+\Delta \mathrm{Pc}=(\mathrm{Phi}-\mathrm{Pho})+(\mathrm{Pci}-\mathrm{Pco})$

To calculate the overall performance of the CFMCHE taking into account both hydrodynamic and thermal performances, a parameter called performance index which is the ratio of CFMCHE effectiveness to the total pressure drop is used[1]:
$\eta=\frac{\varepsilon}{\Delta p t}$

The pumping power required to circulating fluids in CFMCHE is:

$P P=\dot{V} \Delta P t$

Where: is the volumetric flow rate $\left(\mathrm{m}^{3} / \mathrm{s}\right)$.

$\dot{V}=v_{\text {in }} A$

There is onother factor called performance factor is defined as the ratio of heat transfer rate over the pumping power, and that used to calculate the overall performance and also to verify the results of performance index [1]:

$\eta^{*}=\frac{q(W)}{P . P(W)}$

\section{Properties of fluids:}

\subsection{Properties of MEPCM suspension:}

MEPCM particles defined as mixture of polymers as a wall material surrounds a core of PCM and to keep the shape and prevent PCM from a leak during change of phase. Fig. 3 is a sketch of single MEPCM particle during melting [12], the studied MEPCM particles has an average diameter of $5 \mu \mathrm{m}$. The materials used for the shell and the core are selected correspod with the transporter fluid. The core material is (n-octadecane) that melting at temperature of about $28^{\circ} \mathrm{C}$, and the shell material from polymethylmethacrylate (PMMA) [13], [14], and [15] Hence, the physical properties of the wall material and PCMs are different the properties of the MEPCM particle must be calculated from the properties of the different components.

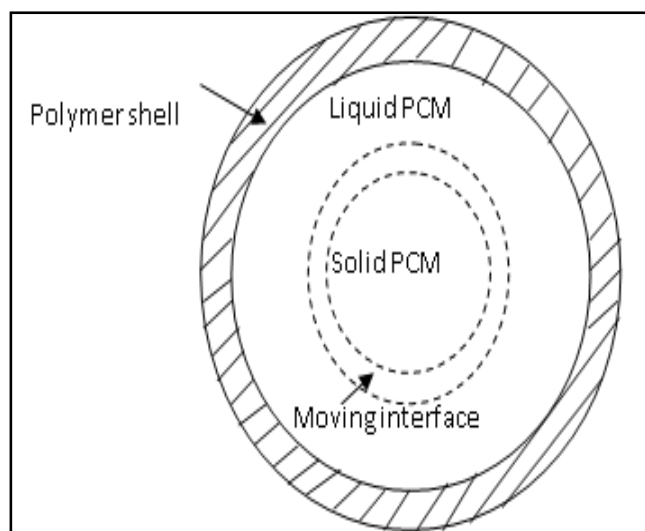

Fig. 3: Sketch schematic of a single MEPCM particle during melting

The density and specific heat of the micro encapsules were calculated by using mass and energy balance respectively, also the density of n-octadecane was taken as the mean of its solid and liquid densities[16].

$\rho_{P C M}=\frac{10}{7}\left(\frac{d_{c}}{d_{P C M}}\right)^{3} \rho_{c}$ 


$$
C p_{P C M}=\frac{\left(7 C p_{c}+3 C p_{\text {wall }}\right) \rho_{c} \rho_{\text {wall }}}{\left(3 \rho_{c}+7 \rho_{\text {wall }}\right) \rho_{P C M}}
$$

The thermal conductivity of the microcapsules given by:

$$
\frac{1}{k_{P C M} d_{P C M}}=\frac{1}{k_{c} d_{c}}+\frac{d_{P C M}-d_{c}}{k_{\text {wall }} d_{P C M} d_{c}}
$$

Where:

PCM: is the particle (capsule = wall+core). Wall: is wall of the capsule (polymer). c: core material (PCM).

d: diameter

The properties of suspension are a mixture of the properties of the microcapsules and the suspending fluid (water), and using a mass and energy balance, the density and specific heat are calculated $[13,16]$.

$\rho_{f}=c \rho_{P C M}+(1-c) \rho_{w}$

$C p_{f}=\phi C p_{P C M}+(1-\phi) C p_{w}$

To calculate the viscosity of the suspension, we use the following relation:

$\mu_{f}=\mu_{w}\left(1-c-1.16 c^{2}\right)^{-2.5}$

The bulk thermal conductivity of suspension was calculated from the relation:

$k_{f}=\frac{2 k_{w}+k_{P C M}+2 c\left(k_{P C M}-k_{w}\right)}{2+\frac{k_{P C M}}{k_{w}}-c\left(\frac{k_{P C M}}{k_{w}}-1\right)}$

The mass fraction can be calculated from:

$$
\phi=\frac{c \rho_{P C M}}{\left(\rho_{w}+c\left(\rho_{P C M}-\rho_{w}\right)\right)}
$$

\subsection{Properties of Nanofluids:}

The thermo physical properties of the nanofluids are depend on the properties of the solid particles, particles shape, the base fluid and volume fraction of the solid particles in the suspension. by using the following relations, the properties of nanofluids can be calculated[17,18]:

Thermal conductivity :

$k_{n f}=k_{f}\left[\frac{k_{p}+(S H-1) k_{f}-(S H-1) c\left(k_{f}-k_{p}\right)}{k_{p}+(S H-1) k_{f}+c\left(k_{f}-k_{p}\right)}\right] \ldots$

Viscosity:

$\mu_{n f}=\mu_{f}(1+2.5 c)$
Density:

$\rho_{n f}=c \rho_{p}+(1-c) \rho_{f}$

Specific heat:

$C p_{n f}=c C p_{P}+(1-c) C p_{f}$

Where SH is solid particle shape factor.

$S H=\frac{3}{\psi}$

$\psi$ : represent the ratio of the surface area of a sphere with a volume equal to that of the particle to the surface area of the particle. For the spherical particles $\mathrm{SH}=3$.

$\mathrm{k}_{\mathrm{f}}, \mathrm{k}_{\mathrm{p}}, \mathrm{k}_{\mathrm{nf}}$ are thermal conductivities of the base fluid, solid particles, and nanofluid respectively.

\subsection{Properties of hybrid suspensions:}

Thermal conductivity and viscosity of hybrid suspension were calculated from the following relations[8].

Thermal conductivity:

$k_{h s}=k_{n f}(1-3 c) / 2$

Viscosity:

$\mu_{h s}=\mu_{n f}(1+7.85 \phi)$

To calculate the density and specific heat of the hybrid suspension, we use the following relations[2].

Density:

$\rho_{h s}=c_{n p} \rho_{n p}+c_{M E P C M} \rho_{M E P C M}+\left(1-c_{n p}-c_{M E P C M}\right) \rho_{b f}$

Specific heat:

$C p_{h s}=\left[\frac{c_{n p} \rho_{n p} c p_{n p}+c_{M E P C M} \rho_{M E P C M} c p_{M E P C M}+\left(1-c_{n p}-c_{M E P C M}\right) c p_{b f} \rho_{b f}}{\rho_{h s}}\right]$.

Where: hs, np, MEPCM, bf reffer to hybrid suspension, nanoparticle, microencapsulated phase change material and base fluid respectively. The properties of materials studied are listed in table (1).

Table (1) properties of materials

\begin{tabular}{|c|c|c|c|c|}
\hline Material & $\begin{array}{c}\rho \\
\left(\mathrm{kg} / \mathrm{m}^{3}\right)\end{array}$ & $\begin{array}{c}\mathrm{Cp} \\
(\mathrm{J} / \mathrm{kg} \cdot \mathrm{K})\end{array}$ & $\begin{array}{c}\mathrm{K} \\
(\mathrm{W} / \mathrm{m} . \mathrm{K}\end{array}$ & $\begin{array}{c}\mu \\
(\mathrm{kg} / \mathrm{m} . \mathrm{s})\end{array}$ \\
\hline
\end{tabular}




\begin{tabular}{|c|c|c|c|c|}
\hline Pure Water & 981.3 & 4189 & 0.643 & 0.00059 \\
\hline $\begin{array}{c}\text { n-octadecane } \\
\text { (MEPCM } \\
\text { core) }\end{array}$ & $\begin{array}{c}\text { solid=850 } \\
\text { liquid=780 }\end{array}$ & 2000 & 0.18 & - \\
\hline $\begin{array}{c}\text { PMMA } \\
\text { (MEPCM } \\
\text { wall) }\end{array}$ & 1190 & 1470 & 0.21 & - \\
\hline $\begin{array}{c}\text { MEPCM } \\
\text { particles }\end{array}$ & 867.2 & 1899 & 0.1643 & - \\
\hline cupper $(\mathrm{Cu})$ & 8930 & 383.1 & 386 & - \\
\hline $\mathrm{Al}_{2} \mathrm{O}_{3}$ & 3600 & 765 & 36 & - \\
\hline
\end{tabular}

used to study the effect of using hybrid suspension as a coolant on the performance of a CFMCHE.

Fig.5 shows the variation of heat transffered with the volume concentration of MEPCM suspension for pure MEPCM suspension and enhanced (hybrid) suspension with adding $2 \%$ and $4 \%$ of $\mathrm{Cu}$ and $\mathrm{Al}_{2} \mathrm{O}_{3}$ nanoparticles.

It can be seen that, decreased in heat transfer with increased MEPCM concentration for all cases because this value of heat transfer represent a sensible heat which decreased due to low value of thermal conductivity of PCM since the heat transferred as a latent heat. Also results reveal that the heat transfer increased with adding

\section{Numerical model:}

A finite volume method is used to transform governing equations to algebraic equations, using a "first order upwind" scheme. The SIMPLE algorithm is employed to enforce mass conservation, and getting the pressure field. The segregated solver is applied to calculate the governing integral equations to the conservation of mass, energy and momentum. A Computational fluid dynamic software (FLUENT 19.1) is used to solve the distribution of temperature, velocity and pressure in a CFMCHE. A mesh was generated through discretizing the computational domain (two channels and the separating wall them) with suitable mesh size by selected after mesh refinement process.

\section{Results and discussion:}

The model were operated first with pure water as a cooling fluid. The inlet temperatures of cold and hot fluids used as boundary conditions are $\mathrm{T}_{\mathrm{ci}}=293 \mathrm{~K}$ and $\mathrm{T}_{\mathrm{hi}}=373 \mathrm{~K}$. Then repeated operating the model by using nanofluid and MEPCM-suspensions with volume fractions of $(2 \%, 4 \%$, $6 \%$, and $8 \%$ ). Noting that a core material of PCM is noctadecane which has $\mathrm{T}_{\text {solidus }}=297 \mathrm{~K}$ and $\mathrm{T}_{\text {liquidus }}=302 \mathrm{~K}$, also latent heat $\Delta \mathrm{H}=245,000(\mathrm{~J} / \mathrm{kg})$. And then repeated again operating the model by adding nanoparticles of $(\mathrm{Cu}$ and $\left.\mathrm{Al}_{2} \mathrm{O}_{3}\right)$ with volume fractions of $(2 \%$ and $4 \%)$ for MEPCM suspension above to the formation the hybrid suspension.

To check the validity of present numerical model, verification was made during solving the numerical model presented in [6] and comparing the numerical results of present model with the numerical results of presented in [6]. The numerical model reference [6] is a micro channel heat exchanger has composed of rectangular microchannels with hydraulic diameter $\mathrm{Dh}=100 \mu \mathrm{m}$, channel height $\mathrm{H}=100 \mu \mathrm{m}$, channel width $\mathrm{W}=100 \mu \mathrm{m}$ and length $\mathrm{L}=10 \mathrm{~mm}$. Channels are separated by a $50 \mu \mathrm{m}$ wall thickness of Silicon and experiment was made with inlet velocity of $\mathrm{Vi}=1 \mathrm{~m} / \mathrm{s}$.

Fig.4 shows the comparison between results of present numerical model and the numerical data of [6] for heat transfer rate distribution with volume fractions. From this figure it can be seen that, the agreement between results of present model and results of [6] is acceptable since the average error is $1.16 \%$ which may be due to the end effect. Hence, the present numerical model is reliable and can be nanoparticles due to enhancing the thermal properties of suspension especially thermal conductivity and this enhancement increased with increasing the amount of nanoparticles volume concentration. The enhancement in heat transfer noted was higher in case of adding $\mathrm{Cu}$ particles compared with particles due to higher value of thermal conductivity of $\mathrm{Cu}$ compared with that for $\mathrm{Al}_{2} \mathrm{O}_{3}$.

Fig.6 presented the variation of pressure drop with the volume concentration of MEPCM suspension for pure MEPCM suspension and enhanced (hybrid) suspension with adding $2 \%$ and $4 \%$ of $\mathrm{Cu}$ and $\mathrm{Al}_{2} \mathrm{O}_{3}$ nanoparticles. It can be found that, increasing pressure drop with increased MEPCM concentration for all cases due to the increase in the viscosity. Also this figure reveal that the pressure drop significantly increased with adding nanoparticles due to increase drastically the effective dynamic viscosity, these viscosity increased with increasing the amount of nanoparticles through volume concentration. There is a small difference between pressure drop is in case of adding $\mathrm{Cu}$ particles compared with $\mathrm{Al}_{2} \mathrm{O}_{3}$ particles due to the difference in density between them.

Fig.7 indicates the variation of effectiveness with the volume concentration of MEPCM suspension for pure MEPCM suspension and enhanced (hybrid) suspension with adding $2 \%$ and $4 \%$ of $\mathrm{Cu}$ and $\mathrm{Al}_{2} \mathrm{O}_{3}$ nanoparticles. Decrease in thermal conductivity observed with increased MEPCM concentration. The figure showed that, when increasing MEPCM concentration for all cases the effectiveness increased due to the release of latent heat through melting of PCM in the suspension.

This figure also shows that the effectiveness increased with adding nanoparticles due to enhancing the thermal properties of suspension especially thermal conductivity and this enhancement increased with increasing the amount of nanoparticles through volume concentration. Most notably that the effectiveness is slightly higher in case of adding $\mathrm{Cu}$ particles compared with particles due to higher value of thermal conductivity of $\mathrm{Cu}$ compared with that for $\mathrm{Al}_{2} \mathrm{O}_{3}$.

The variation of performance index with the volume concentration of MEPCM suspension for pure MEPCM suspension and enhanced (hybrid) suspension with adding $2 \%$ and $4 \%$ of $\mathrm{Cu}$ and $\mathrm{Al}_{2} \mathrm{O}_{3}$ nanoparticles is showed in fig. 8

Reduction in performance index with increased MEPCM concentration for all cases due to the increasing in pressure drop and was higher than the increasing effectiveness. Also results reveal that the performance 
increased slightly with adding nanoparticle due to increasing thermal conductivity under, enhanced the effectiveness, and this enhancement increased with increasing the amount of nanoparticles through volume concentration. Besides that the performance is slightly higher in case of adding $\mathrm{Cu}$ particles compared with $\mathrm{Al}_{2} \mathrm{O}_{3}$ particles due to higher value of thermal conductivity of $\mathrm{Cu}$ compared with that for $\mathrm{Al}_{2} \mathrm{O}_{3}$, hence, the effectiveness is greater.

Fig.9 presents the variation of pumping power with the volume concentration of MEPCM suspension for pure MEPCM suspension and enhanced (hybrid) suspension with adding $2 \%$ and $4 \%$ of $\mathrm{Cu}$ and $\mathrm{Al}_{2} \mathrm{O}_{3}$ nanoparticles. It can be noted that, increased in pumping power with increased MEPCM concentration for all cases due to the increase in pressure drop. Increased in pumping power significantly found with adding nanoparticles due to increase in pressure drop resulting from increase drastically the effective dynamic viscosity. Also pumping power seen increased with increased the amount of nanoparticles through volume concentration. There is a small difference between pumping power is detected in case of adding $\mathrm{Cu}$ particles compared with $\mathrm{Al}_{2} \mathrm{O}_{3}$ particles due to the difference in density and viscosity between them, that produces different pressure drop.

The variation of performance factor with the volume concentration of MEPCM suspension for pure MEPCM suspension and enhanced (hybrid) suspension with adding $2 \%$ and $4 \%$ of $\mathrm{Cu}$ and $\mathrm{Al}_{2} \mathrm{O}_{3}$ nanoparticles has been displayed in fig. 10

It can be seen that, the performance factor is decreased with increased MEPCM concentration for all cases due to the increase in pumping power and was higher than the increased heat transfer rate. As well the performance factor increased slightly with adding $\mathrm{Cu}$ nanoparticles due to enhance the heat transfer rate the resulting from increasing thermal conductivity and enhancement increased with increased the amount of nanoparticles through volume concentration. In contrast for $\mathrm{Al}_{2} \mathrm{O}_{3}$ nanoparticle. The performance factor is slightly higher in case of adding $\mathrm{Cu}$ particles compared with $\mathrm{Al}_{2} \mathrm{O}_{3}$ particles due to higher value of thermal conductivity of $\mathrm{Cu}$ compared with that for $\mathrm{Al}_{2} \mathrm{O}_{3}$, hence, the heat transfer is higher.

\section{Conclusions:}

From the obtained results in this paper, the following conclusions can be made:

1. The MEPCM suspension can be enhanced by adding nanoparticles to obtain hybrid suspension.
2. Using of higher thermal conductivity nanoparticles lead to obtain extra enhancement in MEPCM suspension thermal performance.

3. Using of hybrid suspension lead to enhance the thermal performance of CFMCHE.

4. Also the hybrid suspension cause extra increase in
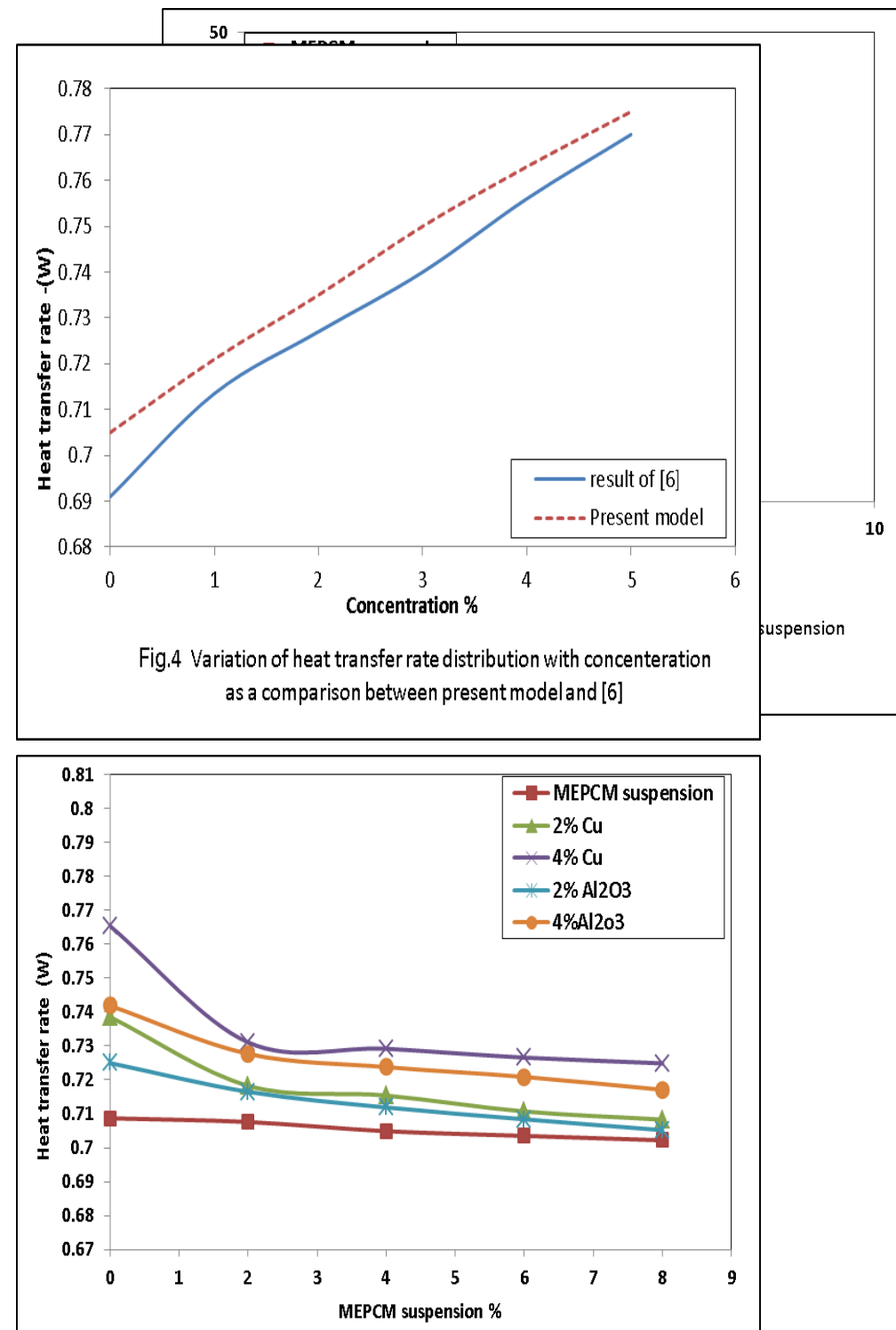

Fig. 5 Variation of heat transfer rate with concentration of MEPCM suspension for different concentrations of nanoparticles.

pressure drop which dominate the thermal performance. 


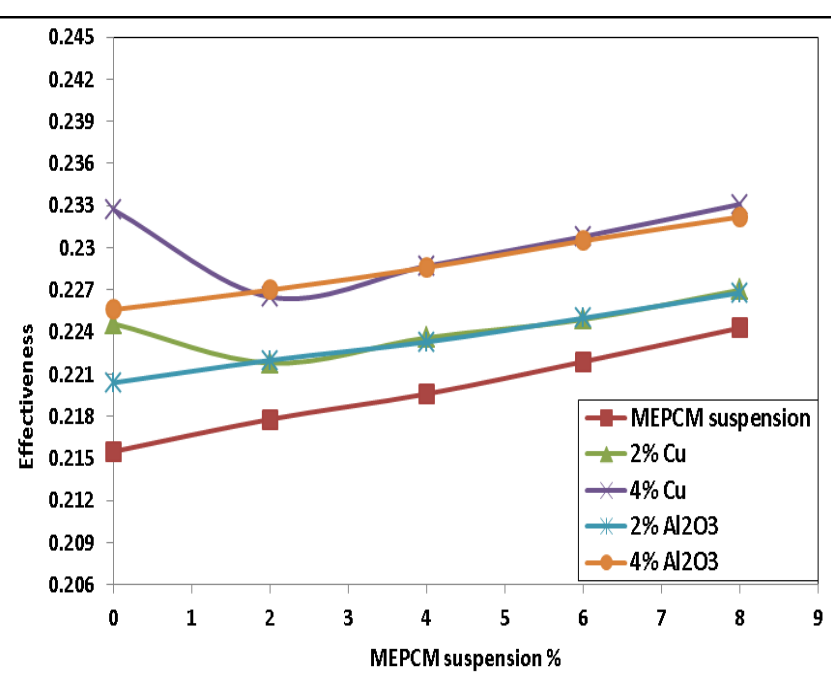

Fig.7 Variation of effectiveness with concentration of MEPCM suspension for different concentrations of nanoparticles

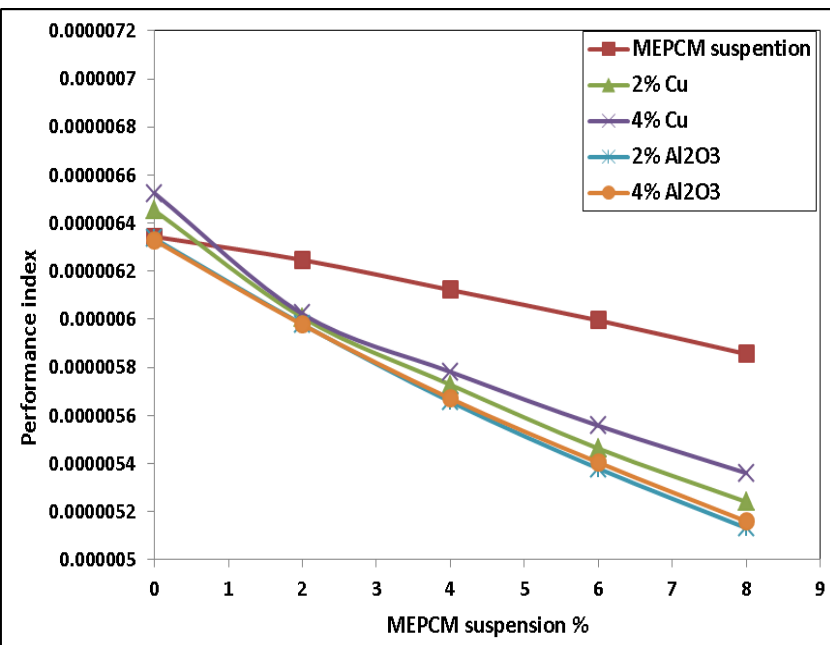

Fig.8 Variation of performance with concentration of MEPCM suspension for differentconcentrations of nanoparticles

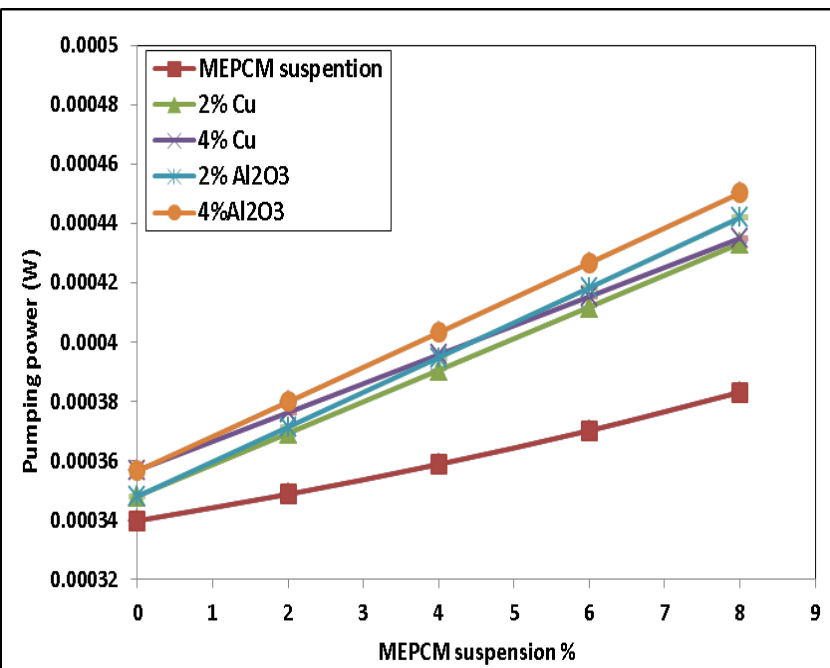

Fig.9 Variation of pumping power with concentration of MEPCM suspension for different concentrations of nanoparticles

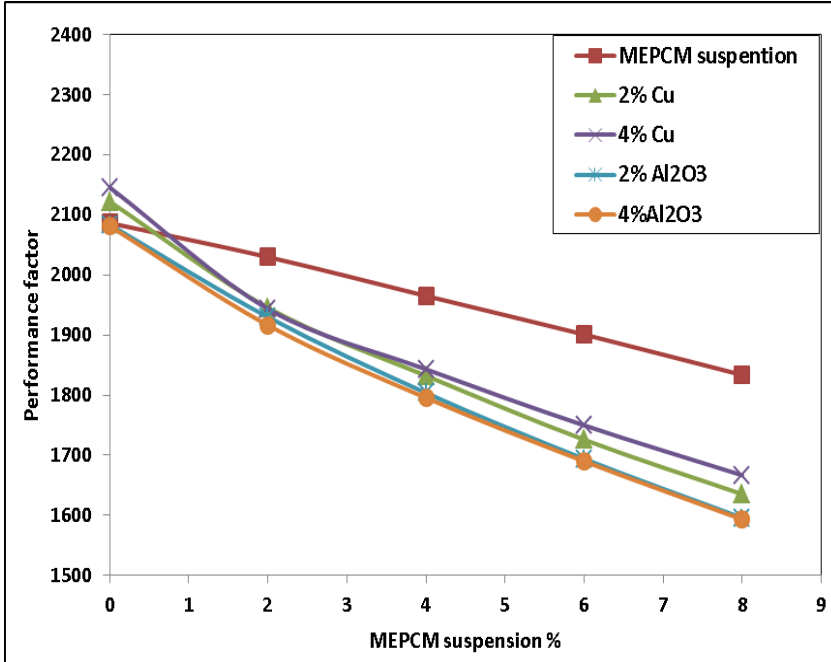

Fig. 10 Variation of performance factor with concentration of MEPCM suspension for different concentrations of nanoparticles

\section{References:}

[1] Mushtaq I. H., A. A. Rageb, M. Yaghoubi, Homayon H., "Influence of channel geometry on the performance of counter flow microchannel heat exchanger", International Journal of thermal sciences, 2009, Vol. 48, pg.1607-1618. [2] C. J. Ho, J.B. Huang, P.S. Tsai, Y.M. Yang, "Preparation and properties of hybrid water-based suspension of nanoparticles and MEPCM particles as functional forced convection fluid" ,International Communications in Heat and Mass Transfer, 2010, Vol. 37, pg. 490-494.

[3] Mushtaq I. Hasan, " Numerical investigation of counter flow microchannel heat exchanger with MEPCM suspension", Applied Thermal Engineering, 2011, vol. 31, pg. 1068-1075.

[4] C. J. Ho, J.B. Huang, P.S. Tsai, Y.M. Yang, "On laminar convective cooling performance of hybrid waterbased suspensions of nanoparticles and MEPCM particles in a circular tube" ,International Journal of Heat and Mass Transfer, 2011, Vol. 54,pg. 2397-2407.

[5] C.J. Ho, Wei-Chen Chen, Wei-Mon Yan, "Experiment on thermal performance of water-based suspensions of nanoparticles and MEPCM particles in a minichannel heat sink " ,International Journal of Heat and Mass Transfer, 2014, Vol. 69, pg. 276-284.

[6] Mushtaq I. Hasan, Abdul A. Rageb, Yaghoubi M., "Investigation of a counter flow micrchannel heat exchanger performance with using nanofluid as a coolant", Journal of Electronics Cooling and Thermal Control, Scientific Research, 2012, Vol. 2, pg. 35-43.

[7] Nabeel S. Dhaidan, J.M. Khodadadi, Tahseen A. AlHattab, Saad M. Al-Mashat, "Experimental and numerical investigation of melting of phase change material/nanoparticle suspensions in a square container subjected to a constant heat flux", International Journal of Heat and Mass Transfer, 2013, Vol. 66, pg. 672-683.

[8] S. Manikandan, K.S. Rajan, "New hybrid nanofluid containing encapsulated paraffin wax and sand 
nanoparticles in propylene glycol-water mixture: Potential heat transfer fluid for energy management", Energy Conversion and Management, Cross mark, 2017, Vol. 137, pg. 74-85.

[9] Mushtaq I. Hasan, Mahmood Yaghoubi, Abdul Muhsen A. Rageb, " Improving thermal performance of a counter flow microchannel heat exchanger by using nanofluid", Fourth International Conference on Thermal Engineering: Theory and Applications, January 12 - 14, 2009, Abu Dhabi, UAE.

[10] Mushtaq I. H., Dhay. M. Muter, " Study the micro heat sink with pin fins and different coolants: a comparative study ", International Journal of Eengineering and Technologe, 2018, Vol. 7 No.4, pg.4856-4865.

[11] Michael J. Moran, Howard N. Shapiro, "Fundamentals of engineering thermodynamics ", Fifth edition, SI Unites, John wiley and Sons, INC., 2006.

[12] Mushtaq I. Hasan, Hind L Tbena. " Numerical investigation of micro-channel heat sink with MEPCM suspension with different type of PCM". AL-Qadisiyah Journal for Engineering Sciences,2018, Vol. 11, No. 1, pg.115-133.

[13] Rao Yu, Frank D., Peter S., "Convective heat transfer characteristics of microencapsulated phase change material suspensions in minichannels", Springer, Heat Mass Transfer, 2007, Vol. 44, pg. 175 - 186.

[14] Yasushi Yamagishi, Hiromi T., Alexander T. P., Naoyuki K., "Characteristics of microencapsulated PCM slurry as a heat -transfer fluid", AIChE Journal, 1999, Vol. 45, No. 4.

[15] Hao Y. L., Tao Y. X., " A numerical model for phase - change suspension flow in microchannels ", Taylor and Francis, Numerical heat transfer, 2004, Part A Vol. 46, pg. 55- 77.

[16] Manish Goel, Roy S. K., Sengupta S., " Laminar forced convection heat transfer in microcapsulated phase change material suspensions ", Int. Journal of Heat and Mass Transfer, 1994, Vol. 37, No. 4, pg. 593 - 604.

[17] T.-H. Tsai and R. Chein, "Performance Analysis of Nano-fluid-Cooled Microchannel Heat Sinks," International Journal of Heat and Fluid Flow, 2007, Vol. 28, No. 5, pg. 1013-1026.

[18] Lee and I. Mudawar, "Assessment of the Effectiveness of Nanofluids for Single-Phase and TwoPhase Heat Transfer in Micro-Channels," International Journal of Heat and Mass Transfer, 2007, Vol. 50, No. 34, pg. 452- 463 .

\section{List of figures}

Fig.1 A schematic model of the counter flow MCHE.

Fig.2 A heat exchange cell consists of hot and cold channels and a separating wall.

Fig.3 Sketch of a single MEPCM particle during melting.

Fig.4 Variation of heat transfer rate distribution with volume fractions as a comparison between present model and [6].
Fig.5 Variation of heat transfer rate with concentration of MEPCM suspension for concentrations of nanoparticles.

Fig.6 Variation of pressure drop with concentration of MEPCM suspension for concentration of nanoparticles.

Fig.7 Variation of effectiveness with concentration of MEPCM suspension for concentration of nanoparticles.

Fig.8 Variation of performance with concentration of MEPCM suspension for concentration of nanoparticles.

Fig.9 Variation of pumping power with concentration of MEPCM suspension for concentration of nanoparticles.

Fig.10 Variation of performance factor with concentration of MEPCM suspension for concentration of 